\title{
UMA EXPERIÊNCIA CLÍNICA NO COURTIL: UMA INSTITUIÇÃO ORIENTADA PELA PRÁTICA ENTRE VÁRIOS
}

A CLINICAL EXPERIENCE AT COURTIL: A PRACTICE-ORIENTED INSTITUTION AMONG SEVERAL

\section{UNA EXPERIENCIA CLÍNICA EN COURTIL: UNA INSTITUCIÓN ORIENTADA POR LA PRÁCTICA ENTRE VARIOS}

\section{Poliane Paula Ferreira Azevedo*}

\begin{abstract}
RESUMO
Este artigo apresenta uma reflexão baseada numa experiência clínica como estagiária em uma instituição belga, denominada Le Courtil, que acolhe crianças e jovens autistas, psicóticos e neuróticos em estado grave. O trabalho do Le Courtil consiste na prática entre vários, que tem a reunião clínica como um dispositivo para elaborar os casos, um a um, e os profissionais que ali atuam visam a abrir para o sujeito a possibilidade de inventar sua própria resposta ao seu sofrimento. Há também um compromisso dessa instituição com a transmissão, por meio de seminários, apresentação de casos e acolhimento aos estagiários. Neste artigo, será realizada a exposição do Courtil e a fundamentação teórica da prática nessa instituição, bem como uma apresentação de recortes da experiência clínica, na qual se ilustrará o trabalho realizado nesse contexto institucional.
\end{abstract}

Palavras-chave: Psicanálise. Instituição. Autismo. Psicose. Estágio.

\begin{abstract}
This article presents a reflection from a clinical experience as an intern at a Belgian institution, called Le Courtil that welcomes autistic, psychotic and neurotic children and young people. The work consisted of the practice among several, which has the clinical meeting as a device to elaborate the case, one by one, and the professionals who work there aimed to open up for the subject, the possibility of inventing their own response to their suffering. There is also a commitment from this institution to the transmission, through seminars, presentation of cases and welcoming interns. There will be an exhibition of Courtil and the theoretical foundation of the practice in this institution, as well as a presentation of parts from the clinical experience, that will illustrate the work done in this institutional context.
\end{abstract}

Keywords: Psychoanalysis. Institution. Autism. Psychosis. Internship.

\footnotetext{
*Especialista em Abordagem Psicanalítica do Autismo e Suas Conexões (Pontifícia Universidade Católica de Minas Gerais - PUC Minas, Instituto de Educação Continuada - IEC), psicóloga. Endereço: Rua Fernandes Tourinho, 470, sala 505 - Savassi, Belo Horizonte-MG, Brasil. CEP: 30112-000.E-mail: poliane.pferreira@outlook.com.
} 


\section{RESUMEN}

Este artículo presenta una reflexión de una experiencia clínica como pasante en una institución belga, llamada Le Courtil, que da la bienvenida a niños y jóvenes autistas, psicóticos y neuróticos. Un trabajo que consiste en la práctica entre varios, que tiene la reunión clínica como un dispositivo para elaborar el caso, uno a uno, y los profesionales que trabajan allí tienen como objetivo abrir al sujeto la posibilidad de inventar su propia respuesta a su sufrimiento. También existe un compromiso de esta institución con la transmisión, a través de seminarios, presentación de casos y acogida de pasantes. Habrá, en este artículo, una exposición de Courtil y los fundamentos teóricos de la práctica en esa institución, así como una presentación de partes de un ensayo clínico, en la que se ilustrará el trabajo realizado en ese contexto institucional.

Palabras clave: Psicoanálisis. Institución. Autismo. Psicosis. Pasantía.

\section{INTRODUÇÃO}

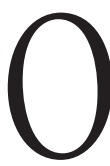

interesse pela escrita deste artigo se originou de minha experiência como estagiária numa instituição belga denominada Le Courtil. Essa instituição foi fundada pelo psiquiatra e psicanalista Alexandre Stevens, em 1982, sendo vinculada ao Institut Médico-Pédagogique Notre Dame de la Sagesse (IMP), que acolhe, desde 1950, crianças e jovens em sofrimento psíquico.

Durante minha especialização em Autismo e suas conexões, pela PUC Minas, foi apresentado e discutido o documentário $A$ ciel ouvert (Otero, 2013), que retrata a prática no interior do Courtil. Esse documentário apresentou as intervenções e seus efeitos no contexto institucional. A partir disso, decidi, no fim de 2018, postular um estágio nessa instituição, que foi aceito em 2019, período em que realizei essa experiência.

As instituições para tratamento de crianças na França e na Bélgica se organizam da seguinte forma: Centre Médico-Psycho-Pédagogique (CMPP), na França, e IMP, na Bélgica. Ambas têm como propósito acolher crianças com diversas dificuldades, como de fala, linguagem, psicomotricidade e desenvolvimento, visando ao tratamento psicoterapêutico.

O IMP Leers-Nord foi inaugurado por um grupo de religiosas, as filles de la Sagesse, na década de 1950. Já no início do trabalho, elas depararam com os desafios de uma clínica com crianças em sofrimento psíquico e avaliaram a necessidade de integrar a equipe de profissionais da área de saúde mental. Sendo assim, recorreram a psicanalistas para assumirem esse trabalho na instituição. 
Mais tarde, em 1974, Antônio Di Ciaccia, movido pelo desejo de um trabalho em uma instituição que pudesse acolher crianças autistas e psicóticas, criou a Antenne 110, situada em Bruxelas. O funcionamento institucional, segundo Di Ciaccia (2007), é estruturado em três eixos. O primeiro consiste na reunião dos membros de equipe, com o propósito de possibilitar uma operação de separação entre o saber adquirido dos adultos e o lugar subjetivo de cada criança. $\mathrm{O}$ segundo diz respeito à função do responsável terapêutico, que é estar atento a como a criança está inserida na linguagem. O terceiro e último eixo é o da fundamentação teórica: a psicanálise de orientação lacaniana.

A Antenne conta com cerca de 30 crianças, que geralmente passam a semana na instituição e vão para casa nos fins de semana. Durante alguns anos, os profissionais que lá atuavam eram orientados pela supervisão de Françoise Dolto. Nesse tempo, eram claramente definidos o lugar destinado aos psicólogos e o dos pedagogos, havia essa divisão. Contudo esse não era o formato de trabalho idealizado para a instituição. Os profissionais, independentemente de sua formação, deveriam ocupar a mesma função: as atividades do cotidiano da casa e as oficinas terapêuticas. Em 1976, as supervisões com a orientação de Dolto foram suspensas. Isso porque, para Ciaccia, a função dos profissionais que ali atuavam seria guiar a criança para que ela conseguisse encontrar sua solução, seu saber, sendo que cabia a esses profissionais possibilitar espaços para que isso ocorresse.

Anos depois, em 1982, o Courtil foi inaugurado pelo psiquiatra Alexandre Stevens, com o apoio de Bernard Seynhaeve, acolhendo aproximadamente 15 crianças. A instituição é parte do IMP, mas atua de maneira independente, orientando-se pela psicanálise, enquanto o IMP se dispóe a acolher uma demanda pedagógica. Como afirma Stevens, o propósito do Courtil era

Fabricar uma instituição particular para cada caso, para cada sintoma, e que devemos nos deixar guiar pela realidade psíquica, feita de linguagem mais do que pela realidade social espacial. É preciso produzir uma instituição tal que permita a existência, no interior dela mesma, de tantas instituições quantos forem os sujeitos que as habitam (Stevens, 2007, p. 77).

Em 1992, o Courtil passou a integrar a Rede Internacional das Instituições Infantis (R13), criada por Jacques Alain-Miller, com a finalidade de fazer com que instituiçõoes de orientação psicanalítica tivessem uma inscrição no discurso social. O R13 agrupa instituições que são fundamentadas por uma transferência de trabalho à Escola da Causa Freudiana e ao Campo Freudiano. É formado por três instituições: Antenne 110 e Courtil, na Bélgica; e Centro Terapêutico e de Pesquisa de Nonnete, na França. Essa rede internacional de instituições infantis 
tem uma responsabilidade com a transmissão da prática clínica por meio de seminários, publicações e também do acolhimento a estagiários no interior de cada uma delas.

A prática realizada no Courtil se sustenta na psicanálise de orientação lacaniana, e essa formação é demandada de todos os que ali trabalham. Como espaços de formação teórica, ocorrem, no interior da instituição, seminários e grupos de trabalho, sempre vinculados ao Campo Freudiano, uma vez por semana. Há ainda uma supervisão individual para interventores e estagiários, também semanalmente. Além disso, é prevista uma apresentação de paciente a cada dois meses, conduzida por um psicanalista convidado. Devido a seu compromisso com a transmissão, o Courtil tem a abertura aos estagiários de todo o mundo, a participação em eventos e as produçōes escritas acessíveis on-line. Em 1989, foi publicada a primeira edição da revista Les Feuillets du Courtil, atualmente também com uma versão on-line, a Courtil en Lignes.

\section{DA NATUREZA DA PRÁTICA NO COURTIL}

Inicialmente, quando inaugurado, em 1982, o Courtil acolheu aproximadamente 15 crianças. Posteriormente, em 1988, duas novas unidades foram criadas e, desde então, a instituição não parou de avançar, tanto em sua estrutura física como no quadro de profissionais, o que possibilitou acolher um número maior de crianças e jovens (entre 6 e 20 anos). Atualmente acolhe, ao todo, mais de 200 internos e semi-internos. Atentos ao sofrimento psíquico e à singularidade de cada sujeito acolhido, os interventores são impulsionados pelo desejo de esclarecer e elaborar sua prática caso a caso, sustentados por estudos e formação permanente. $\mathrm{O}$ acompanhamento clínico da instituição coloca entre parênteses o saber estabelecido e o senso comum para dar lugar à surpresa e à bricolagem, que a criança inventa a partir de um material concreto ofertado pelos interventores. ${ }^{1}$

O trabalho no Courtil avançou cada dia mais em sua prática e extensão desde que ele foi fundado. Foi produzido um estilo, ou estilos, de trabalho, como afirma Stevens (2007): "O Courtil é menos um ato de fundação do que uma série de bricolagens para reorientar incessantemente a instituição pela psicanálise" (p. 78). Stevens deixa bem claro que o ponto norteador desse trabalho é a clínica, desde a acolhida de uma criança nesse dispositivo.

No momento em que uma criança e seus pais demandam o acolhimento na instituição, é realizada uma primeira entrevista com o diretor do Courtil, etapa 
fundamental de acolhida e esclarecimento para os pais que seu saber em relação à criança é muito importante. Embora os profissionais que ali atuam tenham prática clínica e formação teórica para sustentar um trabalho com essas crianças, o que interessará durante todo o acompanhamento será o saber de cada sujeito e as soluções por ele encontradas. O que orientará o funcionamento da instituição, como afirma Stevens (2007), não serão as exigências dos especialistas, mas as do sujeito. Os interventores deverão estar ali atentos quando algo do sujeito aparecer.

No Courtil, há uma equipe de profissionais de diversas especialidades. Entretanto, independentemente de sua formação acadêmica, são nomeados como interventores. Eles se ocupam da vida cotidiana da casa: o despertar, o deitar, a higiene, as refeições, o trabalho e também o que eles nomeiam como "ateliês". Esses são dispositivos para acolher as invenções das crianças e são criados com base na demanda delas próprias.

A "prática entre vários" é o que sustenta o trabalho no Courtil. Tal termo foi criado por Miller durante a Terceira Jornada da Rede Internacional de Instituição Infantil, ${ }^{2}$ que se passou em Bruxelas em 1996. Stevens (2007) propõe quatro eixos para pensar a prática entre vários: a "desespecialização", a formação, a invenção e a transmissão.

A desespecialização, como aponta o autor, é um princípio fundamental para a psicanálise aplicada, marcando que a prática entre vários se distingue inteiramente da prática que é nomeada por trabalho pluridisciplinar. Neste segundo caso, cada um trabalha segundo sua especialidade: médico, fisioterapeuta, educador, psicanalista. Portanto a prática entre vários é o contrário disso, pois, na instituição, o psicanalista não é um especialista do sujeito ou do gozo. Ele é um desespecializante, visa a um esvaziamento do saber, ocupa um lugar que possibilita a construção do caso que atravessa todas as perspectivas dos especialistas. $\mathrm{Na}$ instituição, a articulação ocorre a partir da clínica do caso. Para isso, existem as reuniōes nas quais se busca localizar a invenção de cada sujeito.

Tomando como referência as instituições de saúde mental no Brasil, nas quais cada especialista concentra em si o seu saber, ou seja, atua de acordo com sua especialidade, eu permanecia de certa forma fixada nesse formato. Logo no início do meu estágio, ao deparar com a demanda de uma criança que precisava passar por uma consulta psiquiátrica, a fim de verificar um ajuste da medicação, perguntei a um dos interventores qual era o ambulatório da psiquiatria. Surpresos com meu questionamento, disseram-me que seria marcada uma consulta com o serviço de psiquiatria da cidade e que, se fosse de meu desejo, eu poderia 
acompanhar a criança no atendimento. Assim, o Courtil tem o cuidado de não concentrar em si todos os serviços de que as crianças precisam. Dessa forma, elas são tratadas e medicadas, quando necessário, por profissionais externos à instituição. Para se locomoverem, muitas vezes, utilizam também transporte público e frequentam escolas públicas de ensino regular ou especial, de acordo com a necessidade de cada uma.

A formação, um outro ponto destacado por Stevens (2007), diz respeito, apesar de a instituição não visar a um saber especialista, a ser fundamental que todos façam sua formação em psicanálise para aplicá-la à prática terapêutica, pois é necessário que todos tenham uma orientação de trabalho em comum. Como explica o autor, os profissionais que ali atuam são sujeitos que estão em análise, não por um imperativo, mas por serem pessoas que têm uma transferência com a psicanálise, como sujeito suposto saber, e têm algo regulado por essa transferência. No Courtil, ocorrem seminários que visam a despertar o desejo de cada um pela psicanálise, abrindo possibilidade para a busca de formação em clínica analítica fora da instituição.

Com relação ao terceiro eixo tocante a essa prática (as invenções do sujeito), como pontua Stevens, nossa tarefa não é de interpretar ao infinito, mas de estarmos prontos para ouvir a surpresa quando ela aparecer. As crianças e jovens que são recebidos no Courtil são de diversas formas expostos a um gozo que não conseguem localizar. $\mathrm{O}$ trabalho possibilitará que esses sujeitos inventem pontos de ancoragem; e não basta o interventor estar atento às invenções, ele deverá em alguns momentos suscitá-las. Não há uma forma para que isso aconteça, cada interventor, ao seu estilo, possibilitará a abertura de um espaço para as invenções.

Como afirma Stevens (2007), o "ponto de basta" da função paterna não operou para os sujeitos psicóticos. Assim, é necessário que eles encontrem outros que funcionam como substitutos dessa função. Importante ressaltar que esses substitutos partirão do saber do próprio sujeito; o saber está do lado destes, e o não saber, do lado dos interventores. Contudo a instituição regulamenta apenas o mínimo necessário, pois, na sua maior parte, é construído um regulamento adaptado a cada caso.

O quarto eixo é o da transmissão, cuja base é reunião clínica da equipe, um dispositivo para a construção do caso clínico, que se manifesta aí como imprescindível para a transmissão. É esse dispositivo que possibilita a circulação da palavra e, com isso, um esvaziamento do gozo de cada membro da equipe. Cada interventor contribui com suas percepçôes do cotidiano, apresenta seu estilo próprio de intervenção, ademais é a partir da discussão em equipe que uma única orientação é sustentada na direção do caso. Portanto a construção 
do caso clínico é fundamental, é o que orienta a equipe em relação aos impasses e possibilidades de trabalho com cada caso. É nesse espaço que é discutida a função da invenção de cada criança e se a equipe deve sustentá-la ou mesmo limitá-la, quando necessário.

Holvoet (2010) pontua que inventar uma instituição para cada criança foi a fórmula que consagrou a prática do um a um, da subjetivação, e o arranjo de dispositivos que permitem a cada um seguir o caminho de seu sintoma. Contudo não há reunião administrativa ou técnica, isso porque toda manobra pode ser considerada clínica.

Stevens (2007) marca que o Courtil não é um modelo. O autor o localiza como uma experiência original de psicanálise aplicada em instituição. O Courtil acolhe estagiários de faculdades belgas e francesas de diversas áreas, como Psicologia, Serviço Social, Pedagogia, Medicina. Há também o acolhimento de jovens profissionais que, por meio do Campo Freudiano, demandam estágio ao Courtil. É recorrente na instituição encontrar estagiários oriundos de vários países. Vários estagiários são aceitos ao mesmo tempo na instituição, entretanto o período de permanência é diferenciado, pois cada um colocará sua demanda.

\section{DO SINGULAR DE CADA CASO: RECORTES DA EXPERIÊNCIA CLÍNICA}

Notemos como ocorre o trabalho com esses jovens com base em recortes clínicos que extraí de meu estágio. No período em que permaneci no Courtil, acompanhei algumas crianças e jovens, elegi esse caso, pois se trata de um sujeito que sempre recorria à presença do estagiário. Importante mencionar que é um caso para o qual a equipe já havia realizado o diagnóstico quando cheguei à instituição.

Exian, um jovem de 16 anos que não sabia ficar sozinho, precisava estar constantemente em contato: fazia as mesmas perguntas inúmeras vezes para se tranquilizar. Se ele não estivesse com o adulto, poderia estar com outros jovens, mas isso se desfazia rapidamente. Ele queria a mesma coisa que o outro, o mesmo objeto, o que irritava alguns. Não havia grande diferenciação entre ele e o outro. O objeto do outro era dele. Às vezes, essa imposição aparecia com uma certa ferocidade.

Nas saídas para atividades externas, ele costumava pedir para pegar o braço de algum profissional da instituição. Se não colocávamos uma distância, isso poderia ir para a invasão do corpo. Ele queria nos abraçar, apertar nosso abraço. 
Em alguns momentos, repetia as palavras do adulto, dizendo "Sim, você está certo, distância".

Eram pequenos marcos que lhe diziam como lidar com o Outro e que the permitiam não se apegar ao Outro de uma forma tão colada no real do corpo. Mas precisavam ser repetidos incansavelmente.

Exian também podia se apoiar em alguns papéis, como o do cozinheiro, do barman, do professor, o que lhe permitia circular e se ancorar a cada dia. As vestimentas eram extremamente importantes para fazer o personagem existir. Ele precisava do terno, da pasta e dos óculos para interpretar o professor ou do avental para ser o cozinheiro.

Todos os dias, quando eu chegava na instituição, ele me perguntava qual seria o momento em que poderíamos ir para a escola. Essa escola foi um cenário construído por ele e pelos profissionais da instituição, no qual havia quadro escolar, mesas e cadeiras. Ele começava me apresentando o programa, o que desenvolveria com os alunos durante a semana. E dizia: "Você será a estagiária do professor, como uma secretária que ajudará a elaborar o plano de ensino e a colocar a classe em ordem". ${ }^{3}$

Ele levava muito tempo para criar cenários em que encenava incorporando sucessivamente a função do professor e do cozinheiro. No entanto, à certa altura, isso se tornava real demais e o agitava. Ao personificar o professor, ele poderia, por exemplo, tornar-se um valentão e ser muito severo com o aluno. Entretanto, no momento em que escrevia as atividades que seriam desenvolvidas, ficava mais apaziguado, assim como nas ocasiões em que se propunha a transmitir aos alunos seu saber sobre a história de Harry Potter.

Porém o que pode ter efeito na fronteira de uma oficina de teatro, delimitando os papéis, uma cena, uma sequência, é invasivo quando é representado fora do contexto. Então era preciso ter cuidado para que ele permanecesse no jogo, na encenação.

Exian tinha muitas perguntas sobre sexualidade. Falava sobre ter uma namorada e que seu tio sugerira que ele voltasse para casa para fazer "você sabe o que", dizia ele. Perguntava para que servia um preservativo. Dizia que estava em um relacionamento com outra adolescente e insistia repetidamente em convidála para a noite de cinema.

Apesar das pequenas soluções e invenções, ainda era difícil para Exian cuidar de uma atividade sozinho. Demandava a presença de um outro a todo momento. Era muito comum ele escolher um estagiário dentro da instituição. 
Em um dos momentos, ele me convidou para um ateliê de cozinha para fazer um tiramisù (um tipo de sobremesa), respondi que não sabia como fazer. Então ele me disse: "Pode deixar comigo, sei tudo sobre cozinha. Você será apenas minha secretária que fará a leitura da receita. As medidas e o modo de fazer eu sei". Em alguns pontos, ele interrompia a leitura e sorria, dizendo: "Preciso te ensinar a pronunciar melhor as palavras. Repete comigo". Isso ocorria devido à minha posição, de fato, de estrangeira ali naquele contexto, havia algo em que eu vacilava algumas vezes em relação à língua, o que dava espaço para que a saída do sujeito como mestre do seu saber pudesse aparecer.

Stevens, em uma entrevista concedida a Tassara, em 2014, sobre o lugar do estagiário na instituição afirma:

Ainda tem algo a mais, eu penso, no estrangeiro. Tem algo da dimensão da outra língua, da voz, com um pouco de sotaque. Se isso que o sotaque traz não torna a voz menos invasiva e que faz com que os jovens aqui se sintam menos invadidos por uma presença quando o estagiário está por perto? (Stevens apud Tassara, 2015).

Era exatamente esse o ponto que aparecia na fala de Exiam, "Prefiro que a estagiária me acompanhe nas aulas, eu posso ensiná-la como escrever, falar melhor o francês, e você, Martin (referindo-se ao interventor), virá apenas quando eu chamar, se surgir alguma dúvida”.

Como afirma Stevens (apud Tassara, 2015), todo estagiário é um pouco estrangeiro em relação à instituição, por não pertencer a ela. É alguém que fundamentalmente não sabe, está do lado do não saber. Lembrando-nos de que, antes de tudo, essa posição do não saber é a do psicanalista. Entretanto o estagiário representa, especialmente em relação ao jovem psicótico, um pouco mais o não saber do que os outros, isso porque ele o representa imaginariamente. Em se tratando desse ponto do não saber, ele dá uma forma particularmente imaginária, que barra um pouco mais o Outro e o torna menos invasivo a priori.

Tomando como referência o contexto institucional, quando os interventores querem instalar de modo simbólico um limite, uma sanção, eles dizem: "Você vai ter de falar com o diretor terapêutico" ou "Nós vamos convocar o diretor". Como afirma Stevens (apud Tassara, 2015), é puramente simbólico, mas instala a dimensão "há um mestre", há um S1. Contudo o estagiário nunca estará nesse lugar, não será convocado a ocupar essa posição. Ele está na instituição, mas, ao mesmo tempo, não pertence a ela, ele retrata um pouco a margem.

Stevens (apud Tassara, 2015) continua a entrevista, ratificando que, mesmo que todos estejam em formação, para o estagiário, isso é mais certo. Especialmente, 
ao se retomar o ponto da transmissão, o estagiário é um elemento importante para que ela ocorra. Os interventores a todo momento têm o cuidado de discutir o caso, as intervençôes com os estagiários, transmitindo, assim, uma experiência clínica, um saber que poderá impulsionar essa prática em outros lugares.

Ao longo do estágio, percebemos que algumas crianças se relacionam de forma particular com os estagiários. Durante o ateliê de música com crianças autistas, que ocorria semanalmente, eu estava ali com elas e os interventores. Cada criança, ao chegar, escolhia seu instrumento, ora cantava, ora dançava, e assim eles conduziam o ritmo do ateliê. Eu, na posição de estagiária, às vezes um pouco sem jeito, ainda tentando me adaptar, era convocada por algumas crianças a cantar em alguns momentos. Certa vez, ao final do ateliê, fui surpreendida por uma criança, tida como não verbal pela família, chamando-me e dizendo: "Até a próxima semana, estagiária brasileira. Bom final de semana".

Tal episódio nos remete à afirmação de Lacan (1975/1986) em Genebra: "Sobretudo verbosos, os autistas". Ou seja, são sujeitos que estão inseridos na linguagem. Entretanto é importante estarmos atentos à especificidade da enunciação deles, pois, como nos lembra Maleval (2017),

Quando um sujeito autista procura comunicar, ele o faz de uma maneira que não coloque em jogo nem o seu gozo vocal, nem a sua presença, nem os afetos. Se há uma constante discernível em todos os níveis de espectro autista, ela reside na dificuldade do sujeito em tomar uma posição de enunciador. Ele fala sem problemas, contanto que não diga (p. 90).

Isto é, muitas vezes, o que aparece são palavras mais emitidas do que faladas. Nada é mais difícil para esses sujeitos do que uma expressão pessoal.

Todavia, como afirma Maleval (2017), é um desafio para os pais encontrarem "instituições em que a educação e os cuidados estejam associados, em que o trabalho seja adaptado ao ritmo do sujeito, e onde se leve em conta a angústia, em vez de combatê-la violentamente" (p. 31). O trabalho com as crianças e jovens no Courtil, orientado pela prática entre vários, nos ensina que tentamos encarnar o dentro e o fora a todo momento, seja nos ateliês com uma presença atentamente distraída, seja em um passeio externo.

Contudo o essencial é nos esvaziarmos de um saber prévio para dar lugar à invenção de cada sujeito, psicótico ou autista. O que importa é que esse Outro sob medida seja construído por cada um e sustentado por todos da equipe, que lidam diretamente com o sujeito. É essa a finalidade do trabalho. 


\section{Laurent, esclarece:}

Uma instituição orientada pela psicanálise não é uma instituição que promove uma escuta passiva, em contraposição a instituições que defendem aprendizagens ativas. Muito pelo contrário, uma instituição orientada pela psicanálise é um lugar onde se desenrola uma intensa atividade, considerada do ponto de vista da presença. A presença do outro é efetivamente uma exigência. $\mathrm{O}$ corpo do outro é necessário para se obter certa estabilização. O desafio, portanto, está em inventar um procedimento singular, adaptado a cada caso, de tal maneira que a presença do outro seja suportável para o sujeito, de modo que o dispositivo permita outorgar-lhe um corpo pelo efeito de duplo que isso implica (Laurent, 2014, pp. 128-129).

O autor continua, "O trabalho de uma instituição orientada pela psicanálise é este: uma intervenção constante do corpo do outro, que éo oposto da especialização das aprendizagens" (Laurent, 2014). Ou seja, o corpo do outro é necessário para obter certa estabilização. O desafio está em inventar um procedimento singular, adaptado a cada caso. Não há hora marcada para a intervenção, mas o interventor deve estar lá, no momento em que o sujeito elabora. Os encontros com as crianças, os momentos em que se tem uma chance de poder dizer-lhes algo podem se dar em espaços institucionais ou fora deles, tanto em momentos de isolamento, de encontros, a sós, como em oficinas coletivas. Não se trata de terapia de grupo, e sim de isolar a singularidade de um sujeito no cerne de um discurso institucional. 


\section{REFERÊNCIAS}

Association de la Cause freudienne. (2016). L'institut de l'enfant: Ri3. Bruxelles: Association de la Cause Freudienne. Recuperado a partir de http://www.ch-freudien-be.org/connexions/ri3-reseau-institutions-infantiles/

Courtil.(2014). Accueil, hébergement, accompagnement. Leers-Nord: Courtil. Recuperado a partir de http://www.courtil.be/courtil/

Di Ciaccia, A. (2007). Inventar a psicanálise na instituição. In: M. B. Motta, \& S. B. Cabral Filho (Orgs.), Pertinências da psicanálise aplicada: trabalhos da Escola da Causa Freudiana reunidos. (pp. 69-75). Rio de Janeiro: Forense Universitária.

Holvoet, D. Editorial. (2010). In Les feuillets du Courtil: psychanalyse et institution (Vol. 32, pp. 7-8). Leers-Nord: Feuillets du Courtil.

Lacan, J. (1975/1986). Conferência em Genebra sobre o sintoma. Opção Lacaniana, (23), 6-16. (Publicado originalmente em 1975).

Laurent, E. (2014). A batalha do autismo. Rio de Janeiro: Jorge Zahar.

Maleval, J.-C. (2017). O autista e sua voz. São Paulo: Blucher.

Otero, M. (2013). A ciel ouvert: entretien avec Mariana Otero. [YouTube]. Recuperado a partir de https://www.youtube.com/watch?v=jKkUUVwKW0Q

Stevens, A. (2007). A instituição: prática do ato. In: M. B. Motta, \& S. B. Cabral Filho (Orgs.), Pertinências da psicanálise aplicada: trabalhos da Escola da Causa Freudiana reunidos. (pp. 76-85). Rio de Janeiro: Forense Universitária.

Tassara, J. (2015). A presença do estagiário numa instituição para crianças com dificuldades psíquicas. (Dissertação de Mestrado). Programa de Pós-Graduação em Psicologia, Faculdade de Psicologia, Universidade Federal de Minas Gerais, Belo Horizonte. 